Tesis. Año 13, 12(14), 2019, 151-170

\title{
Formación de mentalidades literarias: Mercurio Peruano, El Pacificador del Perú y La Abeja Republicana
}

\author{
Inés Liliana Ramírez Durand
}

\section{Resumen}

En este trabajo investigo fuentes periodísticas de la Emancipación: Mercurio Peruano, El Pacificador del Perú y La Abeja Republicana, hitos de la expresión literaria del periodo y cimientos de la publicación libre de regulaciones editoriales impuestas por el sistema español. Sobre la base de estos diarios (1970 - 1822) establecemos, desde los contenidos artísticos, una comparación entre las intencionalidades discursivas de los editores y de los enunciadores sobre la base de algunas epístolas, poemas y notas, que muestra una estrecha relación entre literatura e historia del Perú. A partir de una revisión cronológica y de la interpretación intertextual y pragmática, encontramos que la producción de literatura nacional se gestaba también en la prensa que, a pesar de las censuras y limitaciones de una seudo "libertad de imprenta", permitió evidenciar y desarrollar formas artísticas, que reflejaban el sentir, la ideología y temas propios, así como las influencias temáticas y de estructura literaria recibidas de Europa.

Palabras clave: diarios, literatura peruana, emancipación, Mercurio Peruano,

\section{Abstract}

This work investigated journalistic sources of Emancipation: Mercurio Peruano, El Pacificador del Perú and La Abeja Republicana, because they are milestones of the literary expression and foundations of the free and open publishing, without editorial regulations imposed by the Spanish system. For this, we reviewed the artistic content of the main newspapers of the Emancipation period (1790-1822), making a comparison between the discursive intentionality of editors and the enunciation upon the basis of letter, poems and notes, showing a close relationship between literature and history of Peru. From a chronological review and intertextual and pragmatic interpretation, we found that the national literature production was also conceived in press which, in spite of the censorship and limitations of the pseudo "freedom of speech", allowed to display and develop art in various ways, which mirrored the feeling, ideology, their own topics as well as the influences on topics and structure coming from Europe. Therefore, we focused on the newspapers.

Keywords: Newspapers, peruvian literature. emancipation, Mercurio Peruano. 


\section{Formación de mentalidades literarias: Mercurio Peruano, El Pacificador del Perú y La Abeja Republicana}

Hablar de Literatura de Emancipación en el Perú significa remontarnos a las primeras formas de difusión pública, es decir, hablar de los principales diarios que no solo van a cumplir con ser canales de información sobre temas políticos, económicos y de eventualidades, sino que también serán el soporte de publicación de ideas libertarias, de poesía y arte de la época. Ahora bien, de acuerdo con Antonio Cornejo Polar, la convergencia de análisis literario sobre la emancipación entre Riva Agüero y José Carlos Mariátegui consiste en señalar que, durante la emancipación, la literatura se centró en temas y formas coloniales que no lograron transformaciones consistentes en el proceso de la formación de una literatura nacional. Por otro lado, ambos proponen dos tipos diferentes de modelo de literatura nacional: Para Riva Agüero, una literatura nacional es aquella de corte hispanista; mientras que, para Mariátegui, debe ser el resultado de las raíces andinas, ya que existe la necesidad de depurar el colonialismo y el cosmopolitismo. A todo esto, Cornejo Polar plantea una diferente forma de explicar una literatura nacional; pues, para él, es imposible buscar la esencia de la literatura nacional en la uniformidad, ya sea en lo puro español o lo puro andino; por el contrario, se trata de analizar y valorar una literatura nacional producto de la multiplicidad y de lo heterogéneo.

En Sobre la literatura de la emancipación en el Perú (1981), para Antonio Cornejo Polar, a pesar de que en los estudios de la literatura peruana se trabaja históricamente el capítulo llamado "Literatura de la emancipación", este periodo se desarrolla con límites imprecisos y centrado en la existencia de obras publicadas alrededor de 1821, y que giran en torno de registros de discursos y textos que valoran los eventos y las ideologías de la época de ese segmento de la historia general del Perú. Para Cornejo Polar, los textos que se producen con fines documentarios son textos circunstanciales y que reflejan aspectos históricos, lo cual consideramos parcialmente cierto, pues, aunque se trate de fondos políticos y libertarios, el estilo artístico y el valor de las publicaciones "históri- 
cas" constituyen un aporte temático a la literatura popular y al arte del uso de la palabra, como el caso de El pacificador del Perú o el Mercurio Peruano.

Por otro lado, ya en el campo netamente literario, Cornejo Polar valora, por encima de todas las manifestaciones del periodo emancipador, la obra de Mariano Melgar y la de José Joaquín Olmedo; del primero resalta las poesías patrióticas y del segundo, la oda A la victoria de Junín. Mientras que, de la oda A la victoria de Junín resalta su vínculo con la historia del Perú. Cornejo Polar fortalece la imagen de Melgar, pues lo saca de la clasificación de poeta simplista en la que muchos lo habían encasillado para señalar que fue Melgar quien sentó las bases de una literatura peruana; asimismo, aclara la diferencia entre la lírica popular y la tradicional para explicar la inscripción de Melgar en la literatura peruana, además de indicar que la breve poesía melgariana, el yaraví propiamente dicho, es el ejemplo de revalorización de la tradición poética nativa que se opone a la tradición elitista y supone un momento importante de nuestra historia, ya que, con la práctica de este tipo de lírica, pasa a un segundo plano la rigidez estilística española.

Continuando con nuestra revisión bibliográfica, consideramos importante resaltar también la periodización de la literatura peruana que Carlos García-Bedoya Maguiña hiciera en el texto Para una periodización de la literatura peruana (1990). Para el autor es importante establecer periodos a partir del marco histórico y social; al respecto, afirma: "Siguiendo a Macera, deslindamos dos grandes etapas en nuestro proceso histórico: una primera de Autonomía andina (hasta la invasión española) y una segunda de Dependencia externa (desde la invasión hasta el presente) (Macera 1977, p. 151)". ${ }^{1}$ En su propuesta, Carlos García-Bedoya señala que el periodo de crisis del régimen colonial comprende de 1730 a 1825, que en un principio se da paralelo al crecimiento del arte cusqueño y la insistencia indígena que busca mejoras de condiciones sociales, la creación del virreinato de La Plata, la crisis por la invasión napoleónica en España y las insurrecciones andinas (Rebelión de Túpac Amaru II y la de Mateo Pumacahua). García-Bedoya resalta, entre las obras más representativas de esta etapa, a El Lazarillo de los ciegos caminantes de Carrió de la Vandera, el Mercurio Peruano, la ideología de Faustino Sánchez Carrión y la obra poética de Olmedo; aunque considera a Melgar como un caso visto como marginal de la literatura de Emancipación.

Por nuestra parte, consideramos que, junto con el Mercurio Peruano, existen otros diarios que aportaron en la ideología de la época, ya sea con tendencias conservadoras realistas o independentistas que, de todas maneras, evidencian el pensamiento peruano y rasgos de las tendencias literarias de entonces; lo cual nos permite enriquecer nuestra visión sobre el pasado histórico y literario, especialmente el género epistolar, ya que en los periódicos se publicaban las noticias 
y eventos mediante cartas. A continuación, algunos ejemplos de epístolas en E1 Peruano (1918) y El Pacificador del Perú (1821):

Soy un recién venido á esta capital, adonde me conduce el deseo de concluir un pleito que tengo pendiente en esta real audiencia. El abogado defensor de mi causa, me dice que estos días va á dar á la imprenta su alegato, y que solo falta la correspondiente licencia de este real tribunal [...] Me valgo de este favor de V.V. para que se sirvan insertar esta carta en su periódico, á fin de que alguno tenga la bondad de esclarecer mi duda, porque siendo forastero sin conocimiento alguno, no tengo con quíen consultarme sobre esta duda, favor que reconocerá Q. S. M. B.

El forastero ${ }^{2}$

Sor. Editor del Pacificador.

MUY Señor mio: como supongo que en el periódico de V. se pueden insertar todos los artículos que sean de alguna utilidad, aunque tengan por objeto censurar las operaciones del General en Gefe, me tomo la libertad de dirigirle este en forma de carta, para que se sirva darlo à luz y proporcionar á mis sentimientos este desahogo, á que creo tengo derecho[...] Disimule V. mi lenguaje, por que no puede usar de otro en el asunto de que se trata.

SOY de V. su atento servidor.

Tupac Amaro ${ }^{3}$

Entre los periódicos que hemos considerado importantes, por lo que aportaron en la formación de la ideología y reflejo literario de la época, están los siguientes:

- El investigador, cuyos números se publicaron entre 1813 y 1814, y en el que se publicara una carta de 1794 dirigida al Inquisidor General de Lima de parte de Fray Diego de Cisneros; en ella protesta sobre la prohibición de la circulación de libros considerados "impropios" para los intereses coloniales. Cabe resaltar que Fray Diego de Cisneros fue quien donara este tipo de textos al Convictorio de San Carlos, durante la administración rectorial de Toribio Rodríguez de Mendoza; asimismo, sería miembro de la Sociedad Amantes del País e, incluso, llegó a ocupar el cargo de secretario de esta sociedad por un periodo breve. No es difícil deducir en este momento que, a partir de la tendencia o línea liberal que mantenía Rodríguez de Mendoza, los estudiantes del Convictorio de San Carlos cumpliesen roles decisivos en la lucha por la independencia del Perú.

- Minerva Peruana (1805- hasta la aparición de La Gaceta del Gobierno de Lima). Su corte era conservador y parcializado con el reino español, pues representaba la voz oficial del reino tanto es así que señalaba en todos 
sus números el título "VIVA FERNANDO VII". Es Minerva Peruana la voz oficial que narrará los hechos entre España y Francia, y que luego decidirían el futuro del virreinato en América, así el 7 de mayo de 1809, por ejemplo, denunció la invasión napoleónica en el reino de España:

Comunicado de oficio a la junta de Córdova. Es indubitable, que el emperador Napoleon vino al frente de sus tropas delante de Madrid en numero de 60 mil infantes, y 8 mil caballos. Desde la noche del $1^{\circ}$ de diciembre hasta la mañana del 3 atacaron alternativamente á las puertas de Fuencarral, Alcalá, y San Bernardo. ${ }^{4}$

Por otro lado, difundía también de manera artística, con dramatizaciones o poemas, el apoyo a Fernando VII, quien buscaba liberarse del yugo napoleónico:

\section{PROCLAMA DEL ECLESIÁSTICO.}

Valerosos guerreros

No con los triunfos hasta aquí adquiridos

Se deben contentar vuestros azeros;

El valor os inflama,

Y desde la opresión de esos vandidos

Nuestro FERNANDO clama,

[...]

Tomen venganza de traición tamaña?

A las armas soldados,

A la victoria, al triunfo, á la venganza,

Corramos denodados

A romper de FERNANDO las cadenas,

$Y$ en la dulce esperanza

De hacer útil la sangre de esas venas

Destruid, asolad y echad por tierra

Ese vil aduar de foragídos:

Sientan pues los horrores de la guerra

Que tienen merecidos

Conseguid peleando

Vengar á Dios y haceros con FERNANDO. ${ }^{5}$

Este poema bélico es, pues, una canción fernandina muy de moda entre los españoles y pueblos de España que estaban en favor del retorno del reinado de Fernando VII. La canción fue publicada oficialmente en la imprenta española Vega y compañía en la primera parte de las estampas "El juego de las provincias de España", el año 1808:

Las palabras del Eclesiástico pronunciadas con todo el entusiasmo que es capaz de infundir el Patriotismo y amor á su Soberano, produxeron en los oyentes tal sensación, que echando mano á la cruz de sus espal- 
das juraron vengar la causa de Dios y de la Patria, sin desistir de tan heroica empresa, mientras existiese uno solo: el Eclesiástico anegado de gozo, los fue abrazando uno después de otro, y viéndoles impacientes por partir, les hecho su santa bendición acompañada de sabios consejos, ofreciéndoles que sus oraciones, ayunos, penitencias y facultades se dirigirían incesantemente al Dios de las batallas para impetrar sus poderosos auxilios en favor de la causa justa. Este ha sido mi sueño y ojalá con su relación pueda yo confirmar á mis generosos compatriotas en sus loables designios, y dispertar á los que yacen aletargados en el odioso lecho de la indolencia, para que todos unidos caminemos por las sendas del honor al templo de la gloria. (Compañía, 1808)

- La Gaceta del Gobierno de Lima, sucedió, como voz oficial del reino, a Minerva Peruana, conservando el título "VIVA FERNANDO VII", y tuvo como principal objetivo promover el orden de la opinión pública, pues se centraba en transmitir noticias en favor del virreinato y en contra de la gesta libertaria:

En el Noticioso de México de 14 de Agosto se dice lo que sigue, y que extractamos aunque de fecha atrasada, para que el público conozca a fondo el atroz carácter de aquellos caribes que ofrecen a la América la felicidad e independencia. $=$ El Editor [...] Ya entonces vió Bolivar conseguidos sus proyectos. La noticia de este inaudito asesinato lleno de horror aun á los más inmorales de su gavilla, y cargó el miserable Piar con toda su execracion. ${ }^{6}$

Como vemos, se adjudicaba a Bolívar la autoría de crímenes sacrílegos en una serie de territorios de América y era calificado como un "ambicioso criminal"; sin embargo, deducimos claramente que se debía a la subjetividad de la imprenta realista.

E1 Peruano. Este diario se publicó entre 1811 y 1812, y se concentra en atacar el poder ejercido por el virreinato y difundir ideas libertarias con matices poéticos como el siguiente:

¡Estupideces esclavos! ¡O...! ¿que fiera, Quando una vez ha roto el duro lazo Vuelve á ofrecer su cuello á la cadena?

Gaspar Rico de Angulo

Los versos pertenecen a una contestación del editor ante la censura que recibiera por tres denuncias de prensa, en un contexto en el que se encontraba en tela de juicio la libertad de imprenta que el virrey Abascal buscaba controlar. 
En el plano literario, este diario tenía por particular característica la inclusión de un extracto del panegírico latino en prosa de Plinio, que figuraba frecuentemente en el encabezado del diario. Esto demuestra el respeto y la imitación por la literatura latina entre estos años, tal como lo vemos, también, en las traducciones al castellano que hiciera Melgar con las obras de Ovidio, el poeta latino.

Por otro lado, si leemos detenidamente esta cita de Plinio nos damos cuenta de que las oraciones están fragmentadas y reordenadas, con respecto de las líneas originales, de la siguiente manera:

Discernatur orationibus nostris diversitas temporum... abeant ac recedant voces illae, quas metus exprimebat: nihil quale antea dicamus, nihil enim quale antea patimur, neque eadem secreto loquimur, qua prius.

Plin. in panegyr. ${ }^{8}$

Por ello, para poder comprender la dirección del mensaje, consideramos necesario revisar la versión original con el correcto orden del extracto citado. Este extracto pertenece al Panegirico que Plinio', el Joven, dedicara en una ceremonia del Senado romano al emperador Trajano, y que consiste en loar la forma de gobernar del Emperador, así como de exhortar a la sociedad a la transparencia y prudencia de opinión. En ese sentido, es de comprender que en el diario se transmita la intención de expresar el sello de transparencia de las publicaciones en un contexto en el que se divulgan las noticias en un ambiente caldeado por conflictos políticos y económicos de Lima. A continuación, el párrafo completo a la cita que se refiere El Peruano:

Equidem non Consuli modo, sed omnibus civibus enitendum reor, ne quid de principe nostro ita dicant, ut idem illud de alio dici potuisse videatur. Quare abeant ac recedant voces illae, quas metus exprimebat: nihil, quale ante, dicamus; nihil enim, quale antea, patimur: nec eadem de principe palam, quae prius, praedicemus; neque enim eadem secreto loquimur, quae prius. Discernatur orationibus nostris diversitas temporum, et ex ipso genere gratiarum agendarum intelligatur, cui, quando sint actae. (Secvndi, 1328)

El mensaje, traducido al castellano a cargo de Francisco de Barreda (1787) expresa lo siguiente:

A mi opinión, no solo un Consul, mas qualquier plebeyo, ha de procurar no decir de nuestro Príncipe cosa que pueda quadrar a otro. Así que enmudezcan aquellas voces que pronunciaba el miedo; no sacrifiquemos lisonjas como antes, pues no padecemos horrores como antes; no digamos del Príncipe en público lo que primero, pues no le murmuramos en secreto como primero. Diferenciemos en nuestras alabanzas los tiem- 
pos, y del mismo género de dar gracias, se entienda á quien y quando se dan. (Plinio, 1787)

Es de suponer que, debido al anonimato de muchas publicaciones, los editores buscasen que sus suscriptores e informantes cumpliesen con un criterio ético antes de solicitar la publicación de sus intereses literarios, ideológicos y personales.

Por otra parte, también es necesario comprender que muchas publicaciones se realizaban de manera anónima o bajo seudónimos, porque Lima era controlada por el Tribunal de la Inquisición de Lima; institución avalada por el rey para castigar a los herejes, y por un virreinato estricto y ansioso por controlar a una población cada vez más deseosa de mejores condiciones y de ser partícipe en la toma de decisiones de esta parte del continente. Por ende, no es de extrañar que los diarios que circulan bajo la regulación virreinal no - son tan expresivos y liberales como los que se difunden una vez llegada la expedición libertadora.

Una vez visto el panorama general periodístico sobre el momento de emancipación, consideramos que para entender mejor a personajes de la literatura de emancipación como Melgar - poeta joven que forma parte de una investigación posterior - hemos considerado revisar con mayor detenimiento tres diarios del periodo emancipador para demostrar cómo se valoraba el arte y se seguían inicialmente tendencias clásicas y renacentistas para desembocar en un estilo que busca una identidad propia, identidad que no podía estar ajena a la realidad histórica que se vivía. Veremos, pues, tres diarios en cuestión: Mercurio Peruano, El Pacificador del Perú y La Abeja Republicana.

\section{E1 Mercurio Peruano}

El Mercurio Peruano fundado por la Sociedad Amantes del País es el diario, cuyo primer número bisemanal (jueves y domingos de cada semana) se lanzó el 2 de enero de 1791, bajo la dirección de José Baquíjano y Carrillo, miembro de la Sociedad Amantes del País, fundada en 1790. Es necesario recordar que es el propio virrey Francisco Gil de Taboada quien aprueba la circulación del mismo y que este debía estar compuesto de 30 académicos, quienes, para incorporarse al derecho de publicación, necesitaban someter a juicio de los censores la calidad de sus producciones. El interés del periódico consistía en transmitir pensamientos de la Ilustración y producción literaria de la época; ya que a fines del siglo XVIII la influencia de las ideologías europeas y el amor a la patria se habían generalizado e hicieron posible el surgimiento de la Sociedad Amantes del País; sociedad que, mediante la investigación intelectual, socializara sus convicciones en este periódico, vigente hasta 1795. 
Los editores del Mercurio, con este trabajo, sustentaban que las ideas debían ser órganos políticos que analizaran la realidad y transformación del país, mediante la publicación de productos artísticos, eventos, noticias y diversidad de anuncios que provocara incremento de conocimiento cultural, histórico y social (minería, construcción, salud, literatura, eventos, etc.). Concluyen, entonces, que se publicarán con el nombre verdadero de los autores solo aquellos poemas, manifiestos o producciones literarias consideradas dignas de serlo.

El primer número del Mercurio describe, en su presentación, aspectos generales y convencionales del territorio del virreinato peruano: en principio, de manera somera, medidas territoriales, superficie y climas; también están los tipos de pobladores que de la región, y se pone énfasis en el tipo de castas reconocidas y sus funciones en la sociedad peruana, más exactamente la percepción que se tenía de las mismas de acuerdo con las labores que desempeñaban en la sociedad. Así, tenemos las categorías siguientes: españoles, indios y negros, consideradas como las castas originales; y las "especies secundarias", como el mulato, quarterón y mestizo, entre los más resaltantes. Por otro lado, se señala el comercio del Perú centrado en la explotación de oro, la producción de azúcar y de lana de vicuña, todos estos como productos de exportación. En este acápite, también se refieren las vicisitudes de producción y extracción de los recursos. Con respecto de la situación indígena en un entorno adverso y opresor, el diario denuncia diplomáticamente la situación del indio, quien integra el grupo menos favorecido:

"El indio con ser pescador à penas come del fruto de su trabajo. Contento con su maíz, sus papas y su chicha, mira la multiplicidad de manjares como una voluntaria mina de la salud y la vida" (Mercurio Peruano, 02-01-1791). ${ }^{10}$

Sin embargo, para Juan Luis Orrego, este grupo no ha comprendido completamente el tema y no lo trata con profundidad, ya que para él: "Existe también un intento por informar el tema andino pero todavía incompleto: la historia de los incas, los restos arqueológicos, pero no al hombre andino de entonces, es decir, los Andes sin indios. Existe una gran desinformación sobre este sector de la población" (Orrego, p. 54).

Por otra parte, también critica la forma de impartir estas actualizaciones y noticias:

Podríamos formularnos la hipótesis que en el Mercurio Peruano hay un interés de ir formando la nación, pero según la doctrina objetiva o Naturalista: conocer la geografía, las costumbres, la economía, el comercio, la historia. No se percibe el interés de ir formando la nación como un producto voluntario, resultado del libre consentimiento de todos los individuos. Además, esto último era imposible dadas las circunstancias de la época, incluso hasta los años de la Independencia. Los criollos 
americanos se nutrieron de una ideología eurocéntrica - léase afrancesada- en una sociedad con una incipiente o casi inexistente burguesía. En el Viejo Mundo, la burguesía fue el vehículo del Estado nacional europeo. En América, contradictoriamente, la Independencia sin burguesía se fundamentó en las ideas de nación y patria. (Orrego, p. 54)

Sin embargo, consideramos que para valorar e interpretar el aporte de la Sociedad Amantes del País, debemos también tener en cuenta que las circunstancias en las que se publicaba eran condicionadas por las reglas, imposiciones y persecución de un régimen virreinal que no está dispuesto a tolerar ningún tipo de protesta o proliferación de ideas libertarias.

Por otro lado, también resaltamos que el contenido de Mercurio Peruano evidencia el pensamiento de la Ilustración, lo cual constituyó un avance importante en la ideología emancipadora:

La Ilustración es general en todo el Perú, tanto por la natural agudeza y penetración de sus habitadores nativos, quanto por su adhesión al estudio. En todo lo que no requiere una meditada combinación de ideas, el Bello Sexo comúnmente hace ventajas al nuestro. La Real Universidad de San Marcos, y con proporción las demás del Reyno, forman un centro de Literatura que lleva abundante luz a toda la circunferencia. Baxo sus auspicios las ciencias del humanista, y del filósofo han hecho en estos últimos tiempos increíbles progresos y los hacen continuamente. ${ }^{11}$

Ya centrándonos en el aspecto literario, entre diversas rimas y composiciones con corte literario, en el folio 31 de Mercurio, encontramos una décima que se publicó y que adjudica su autoría a un jugador de profesión que usa como base unos versos de la décima de Tomás de Iriarte y una glosa que el mencionado jugador decide publicar con motivo de una recepción de dinero considerable. La décima reza así:

DÉCIMA

Tocando la lira Orfeo

$Y$ cantando Jeremias,

Baylaban unas folias

Los hijos de Zebedeo:

En esto el Dios Hymeneo

Llamó á la casta Susana,

Que asomada a la ventana,

se rascaba la mollera;

Y la dixo iquien te viera,

Gran duquesa de Toscana! ${ }^{12}$

En esta décima, se evidencia como alocutario al personaje quien era protectora de Galileo Galilei: la gran duquesa de Toscana. Es necesario señalar que 
Galileo escribe Carta a la señora Cristina de Lorena, gran duquesa de Toscana, la dama a quien va dirigida la obra Cristina de Lorena, a la Duquesa de Pisa; y la obra en cuestión trata sobre el problema de la religión y la ciencia, y goza de un gran valor literario por contener crítica. En el documento Galileo resalta la necesidad de interpretar la Biblia con sentidos no literales; ya que muchas de las nuevas teorías que planteaba sobre la Tierra y el universo no se ajustaban a lo que la Biblia planteaba, y que más bien, los datos indicados en esta última debieran ser tomados como información en sentido figurado; es decir, no literal.

En el Mercurio Peruano también tenemos redacciones de experiencias vividas por personajes que publicaban con fines moralizadores, didácticos, médicos, entre otros. Como el caso del texto de "Salud pública", cuyo autor es bien visto por los editores, debido a su aporte sobre la base de sus conocimientos empíricos.

CARTA ESCRITA A LA SOCIEDAD SOBRE EL ORIGEN de las enfermedades, que regularmente padecen los que desde esta capital vuelven a la Sierra y modo de precaverlas.

\section{SEÑORES AMANTES DEL PAÍS}

Después de haber pasado en la Sierra la parte más florida de mi edad, no hallo otro árbitro para hacer todavía algún papel en el gran mundo, sino el de presentarme como literato, y como filósofo[...] Esta, señores míos, son las reflexiones que he hecho sobre el modo de viajar a la sierra, especialmente en el regreso de esa Capital: no diré que son las mejores que se pueden hacer sobre esta materia; pero sí aseguraré que van acompañadas de mucha ingenuidad; y con las misma ruego a Dios guarde la vida de Vms. y felicite su virtuosa Sociedad por muchos años = B.L.M. de Vms. Su afectísimo servidor.

\section{P. Montalvo ${ }^{13}$}

Las cartas recurrentes, como ya lo hemos visto en nuestro análisis de $E l$ Peruano y El Pacificador del Perú, evidencian que el género epistolar era practicado con mayor frecuencia durante esta etapa en nuestro país, debido a que las publicaciones eran producto de la correspondencia que recibían los editores en la ciudad. También lo eran los seudónimos por medidas de protección de sus autores; por ejemplo, en el folio número 47 de Mercurio Peruano del día 23 de enero de 1791 bajo el título de "Historia de la Sociedad académica de Amantes del País", y principios de, Mercurio Peruano hallamos la explicación del porqué se empleaban los seudónimos para indicar el autor de notas, epístolas, poemas o traducciones líricas, que dicho sea de paso evidencian la imitación y admiración por los estilos griegos de los grupos cultos de la época.

Son varios los pareceres que hay en el Perú sobre la erección de nuestra Sociedad, y sobre el origen de este papel periódico, que nos creemos 
obligados a descubrir los principios, misterios o grecismo, es la positiva enumeración de los Socios, y sus nombres verdaderos: puede que no pase mucho tiempo sin que nos demos a conocer aún por esta parte. ${ }^{14}$

En el folio 49 encontramos la historia de un personaje, cuyo seudónimo es Hesperiófilo, conoce a Hermágoras, Homótimo y Mindírido, Agelasto y Aristio, con quienes participa de las tertulias nocturnas del grupo. En estas, los temas amatorios estaban desterrados, ya que el grupo se consideraba filosófico. Este grupo peculiar, describe la nota, buscaba el desarrollo del intelecto y el fomento de la literatura, razón por la que se hicieron llamar Jóvenes Filarmónicos, que luego se desmembró por los rumbos de la vida que cada uno de sus miembros tuvo que asumir, ya sea por radicar en la sierra, por trabajo o enfermedad. Luego de dos años de ausencia, cuatro de sus miembros se juntaron para continuar con las jornadas, con Aristio a la cabeza como distribuidor de las tareas, implementaron el registro escrito de sus disertaciones como medio de perennizar los productos literarios que tenía como eje temático el amor nacional. De allí que asumen el nuevo nombre Amantes del País empleando el "velo etimológico".

En una publicación, cuenta el folio 52 del número 7 del Mercurio, un joven, cuyo seudónimo es Alcestes, y otro Homótimo pudieron glosar en décimas sobre las concepciones de amor, luego de un intercambio de opiniones sobre el tema señalado y en el que Alcestes opinaba que el amor consistía en deseo de la mujer y complacencia del hombre. Las glosas de pie forzado solicitadas, por el Presidente de la junta para sosegar la discusión, debía terminar con el verso "Júpiter con la lluvia de oro". Las glosas compuestas fueron las siguientes:

Glosa de Homótimo

Regalar á la que quiero

para conseguirla ufano, es un afan cortesano.

que degenera en grosero:

que en el amor verdadero

dedicado á la que adoro,

el interes por vil lo desprecio;

y nunca estuvo mas necio

Júpiter, que en lluvia de oro.

Glosa de Alcestes

Yo que en materia de amar

puedo dar mi parecer,

por que me he visto querer

quando he tenido que dar,

dificulto contrastar

sin interés lo que adoro: 
que siempre al mayor decoro

venció el interés, no el labio,

y nunca estuvo mas sabio

Júpiter, que en lluvia de oro. ${ }^{15}$

Lluvia de oro o lluvia dorada es una fantasía escatológica en la que Júpiter (Zeus) ultraja a Danae, quien es la hija de Acrisio, rey de Argos, y es encerrada en un sótano para que el hijo futuro de esta no mate al rey; ya que, de acuerdo con el oráculo consultado, su nieto, primer hijo de Dánae, lo mataría. Es así que Júpiter cambiará su forma material en lluvia de oro y se encargaría de engendrar mediante esta lluvia que desciende sobre la fértil Danae. El mito de Perseo nace con la lluvia de oro, que fecunda a Dánae, imposibilitada de tener contacto con un hombre.

Dicho esto y con debate iniciado, el autor de la nota aclara que Alcestes sale de la sala de reunión y plantea inmediatamente su concepto de amor y de respeto por las damas y sanciona a los varones que no centran su atención en el buen aprecio de la mujer y el amor.

Ante tanto alarde y lisonjas, Hesperiófilo, carente del talento de versar, decide demostrar que un hombre puede despedirse de la mujer amada sin ser grosero o falto de respeto con la traducción de una famosa aria de Metastassio $\left(\right.$ Folio 53) ${ }^{16}$, famoso escritor dramaturgo y poeta italiano nacido en 1698.

\section{LA DESPEDIDA A NICE}

1. Llegó el instante amargo:

a Dios, Nice mi vida.

¡Después de tu partida

qual viviré sin ti!

Viviré siempre en duelo, sin paz y sin consuelo, ¡y tú quizás bien mío, te olvidarás de mí!

2. Sufre que en ti se ocupe mi pensamiento ansioso, buscando aquel reposo, que hallar no puedo en mí:

Con él en tu camino te seguiré muy fino; ¡y tú quizás bien mío, te olvidarás de mí! [...]

3. Ve aquí, diré, aquel Río donde miróme erguida, 
y luego arrepentida

pedirme paz la vi:

Allí esperar me hacía....

aquí con migo ardía.....

¡y tú quizás bien mío,

te olvidarás de mí!

[...]

4. Piensa qual dulce flecha me dexas en el seno piensa que de amor lleno siempre seré qual fui Piensa, mi vida, en esta separación funesta... piensa ... ah ¡quizás bien mío, Te olvidarás de mí!

\section{ARTES.}

Pietro Metastasio fue uno de los más resaltantes libretistas de ópera del siglo XVIII. Su verdadero nombre fue Pietro Antonio Domenico Bonaventura Trapassi y fue protegido por la princesa Pinelli di Sangro de Nápoles. Entre sus obras, Didone abbandonata, dramma per música (Dido abandonada). Es una de las obras que hasta la actualidad es representada en grandes teatros.

\section{El pacificador del Perú.}

Su primera publicación se dio el 10 de abril de 1821 (la primera de once números) y en el que se aclara cuál era la temática del mismo en el prospecto firmado por la Imprenta del Ejército Libertador:

Este periódico se publicará el 10, 20 y 30 de cada mes en un pliego entero con el título de El Pacificador del Perú. Todos los hombres ilustrados del territorio que se halla bajo la protección del Ejército podran remitir libres de parte al Administrador de la Imprenta los artículos comunicados que quieran hacer al Editor, los que se publicarán oportunamente, cuando no halla alguna razón que lo impida. Para que se distingan los artículos del Editor de los demás con que sea favorecido, tendran siempre al pié la palabra mas llena de sentido que hay en el Diccionario de la lengua humana "Libertad" Se insertarán en este periódico no solo los artículos de política relativos a las actuales circunstancias, sino todos los que tengan conexcion con las artes y ciencias y particularmente con la estadística del país... ${ }^{17}$

Como vemos, este diario es uno de los primeros del país independiente y busca esencialmente el respeto de la libertad de expresión en todos los temas tratados; entre ellos, la literatura no es una excepción. Así lo refleja la siguiente 
composición publicada en el número 1 de este periódico. Se trata de unas palabras que un Caballero invitado pronunciara en una reunión organizada por el General en Jefe de Perú en honor del General Manuel Abreú, comisionado enviado por el Rey de España para conversar sobre la conciliación entre España y las tropas lideradas por Don José de San Martín en marzo de 1821:

\section{BRINDIS}

... En las aras sagradas

De mutua libertad!

Mas si acaso obstinadas

Las Españolas Cortes

Osaren atentar

Contra la Independencia

(¡Este don celestial,

Encanto de la vida!)...,

Continuen los estragos,

Ardamonos en guerra,

Corran de sangre mares,

Amontónense escombros,

$\mathrm{Y}$ antes que ser esclavos

Bajemos á la tumba...

¡Allá no habrá tiranos! 18

En este diario también hay la poesía que refleja el optimismo de tener una patria consolidada. A continuación, una traducción de poesía inglesa, cuyo firmante traductor responde al seudónimo de Pope:

Extiende, ò bella Paz, tu dulce imperio

De mar à mar; $y$ la conquista cese,

Y no haya mas esclavitud. El Indio

En su nativa selva esento, goze

Los frutos de su suelo, y los amores

De sus rojas beldades Perù vea

Otra estirpe Real, y se levanten

Mègicos nuevas, coronadas de oro

Traducción de Pope ${ }^{19}$

Es curioso resaltar que en esta edición juegan con el rol del lector indicándole que en un siguiente número hallarán el nombre del poeta inglés a quien pertenecen los versos. Excelente forma de deleitarnos con literatura e historia.

\section{La abeja republicana}

Faustino Sánchez Carrión (1787), ideólogo del siglo XIX peruano, dirigiendo de las sesiones del Primer Congreso Constituyente republicano, apuesta 
por la república independiente. Ingresó joven al Seminario de San Marcelo en Trujillo, al igual que muchos letrados de la época, que después declinará la vocación religiosa y buscará seguir Derecho, se instaló en Lima en donde estudió en Convictorio de San Carlos (actual Universidad Mayor de San Marcos), que por entonces se encontraba bajo la dirección de don Toribio Rodríguez de Mendoza.

Ataca ideológicamente el sistema colonial y es partidario de la promulgación dela Constitución Politica de la Monarquía Española promulgada en Cádiz en1812, la cual proponía una monarquía constitucional, es así que un principio, gracias al desarrollo del pensamiento democrático, va a apoyar la Constitución monárquica de Fernando VII, inspirada por los liberales españoles; y que, con el tiempo, será abolida (1814) por el mismo rey Fernando VII, una vez que recupere su reino del impuesto por José Bonaparte I. Se trataba, pues, de una carta monárquica que inspira discusiones y análisis en San Carlos, ya que en ella se propone la constitución de Cortes integradas por Diputados elegidos por juntas electorales en todo el territorio español (América y Europa). Estos representantes tendrían, entre otras, las siguientes facultades:

\section{CAPÍTULO VII}

De las facultades de las Cortes.

Art. 131. Las facultades de las Cortes son:

Duodécima. Fijar los gastos de la administración pública.

Décimotercera. Establecer anualmente las contribuciones e impuestos.

Décimocuarta. Tomar caudales a préstamo en casos de necesidad sobre el crédito de la Nación.

Décimoquinta. Aprobar el repartimiento de las contribuciones entre las provincias.

Décimosexta. Examinar y aprobar las cuentas de la inversión de los caudales públicos. (Cádiz, 1812)

A partir de su loable rendimiento en San Carlos, Sánchez Carrión es elegido por Toribio Rodríguez de Mendoza, rector del claustro, como el iniciador del homenaje en favor de José Baquíjano y Carrillo, quien había sido nombrado Consejero de Regencia de España e Indias Estado en España. Con el tiempo, fue profesor del Convictorio de San Carlos y propiciador de las ideas independentistas, se opuso a la continuación de una monarquía.

Una de las formas que encontró para difundir sus ideas de independencia de la monarquía se centra en la publicación de sus discursos a manera epistolar en el diario La Abeja Republicana, diario cuyo número primero data del 4 de agosto de 1922, una semana después de la renuncia el ministro Bernardo Mon- 
teagudo (25 de julio de 1822). Su primer número salió a la luz el 4 de agosto de 1822.

El número 4 del 15 de agosto de 1822 inicia con el pedido del Solitario de Sayán para que se pueda publicar la carta que ha compuesto para que su fin temático "la inadaptabilidad del gobierno monárquico al Estado libre del Perú"20 y que por motivos de censura en marzo del mismo año en el Correo mercantil no pudo ver la luz; por ese motivo, pide que se publique la misiva en La Abeja Republicana. La carta, señala su autor, data del 6 de agosto y en una justificación del narrador a su interlocutor (editor de La Abeja Republicana), así solicita el Solitario de Sayán la publicación de la misma:

Molesto a $V$. con la cartita, suplicándole que la imprima en su periódico toda entera, menos porque lo merezca, que por guardar el hilo del discurso, cortado en marzo, advirtiendole, que seguiria callado, si varias personas, á quienes respeto mucho, no me hubieran estimulado á esta remisión. Digo á $V$. con la modernisima: Que le asegura los sentimientos de toda sv consideración y aprecio- El Solitario de Sayan.

La epístola es sin duda la estrategia eficaz para publicar las ideas libertarias y sus publicaciones constituyen un gran aporte a la literatura y a la documentación sobre historia del país.

\section{Conclusiones}

Los diarios aportaron eficazmente en la difusión de noticias, notas, cartas y poemas que permitieron posteriormente el cambio de pensamiento y la construcción ideológica de nación peruana, ya que esto fortaleció el desarrollo de un ambiente intelectual al que no todos podían acceder, pues no todos los ciudadanos pertenecían a una elite universitaria y carecían de la lectura de textos libertarios, literarios, entre otros, como los que tenían en su haber el Convictorio de San Carlos u otras instituciones del virreinato.

Consideramos que es el Mercurio Peruano el que marca el inicio de la divulgación de cultura letrada y académica, aunque con restricciones de los medios por parte de la Corona Española, busca generar la idea de nación. Lo mismo ocurre con El Peruano y otros; pero solo fue cuestión de tiempo para que las ideas libertarias se gesten y expresen con mayor libertad, lo cual dio paso a que los intelectuales, literatos, profesionales y estudiantes busquen la identidad con una nueva nación independiente y formas poéticas que se identifiquen más con sus raíces, tal fue el caso de Mariano Melgar, quien dio un cambio a su vida y composiciones de traducciones al castellano de clásicos latinos, creación de fábulas al estilo neoclásico, hasta composición de Yaravíes. Finalmente, la 
libertad ideológica, de expresión literaria se da gradualmente con El Pacificador del Perú, para ser continuado, en diarios próximos como La Abeja Republicana.

\section{Notas}

1 García Bedoya, Carlos. Para una periodización de la Literatura Peruana. 1990 Lima- Perú. Latinoamericana Editores, p. 59.

2 El Pacificador del Perú , p. 4- 5. 10 de abril de 1821.

3 Íbidem

4 Minerva Peruana. $\mathrm{N}^{\circ}$ 35, 7 de mayo de 1809.

5 Minerva Peruana. N 8, p.p. 96-97, 26 de enero de 1809.

6 La Gaceta del Gobierno de Lima. Número 27.

7 El Peruano. Gaspar Rico de Angulo, pp. 436, 9 de junio de 1812.

8 El Peruano. Gaspar Rico de Angulo, p. 309, 28 de abril de 1812.

9 Plinio "el Joven", cuyo nombre verdadero fue Plinius Caecilius Secundus había compuesto diversos panegíricos en honor del emperador romano Trajano, para quien trabajaba como juez que sancionaba a los creyentes cristianos para no ejecutarlos, obligándolos a negar su fe y rendir culto a los dioses romanos, así como al emperador Trajano. El Panegyricus Traianies es una obra que centra su atención en la adulación a Trajano y su gestión política, económica, entre otras.

10 Mercurio Peruano. Folio 6, 2 de enero de 1791.

11 Mercurio Peruano. Folio 7, 2 de enero de 1791

12 Mercurio Peruano. Folio 31, 3 de enero de 1791.

13 Mercurio Peruano. Tomo I, folio 47, 1791.

14 Mercurio Peruano. Tomo I, Folio 47, 1791.

15 Mercurio Peruano. Número 7, 23 de enero de 1791.

16 Mercurio Peruano. Número 7, 23 de enero de 1791.

17 El Pacificador del Perú. 10 de abril de 1821.

18 El Pacificador del Perú. 10 de abril de 1821.

19 El Pacificador del Perú. 10 de abril de 1821.

20 La Abeja Republicana, Número 4, 15 de agosto de 1821. Lima

\section{Referencias}

Amaro, T. (1821). El Pacificador del Perú. Lima

Angulo, G. R. (1812). Defensa. El Peruano. Lima

Cádiz, C. d. (1812). Constitución Política de la Monarquía Española.

Compañía, I. d. (1808). El juego de las provincias de España : Sueño. Madrid: Ma- 
drid en la imprenta de Vega y Compañia.

Cornejo, A. (1981). Sobre la literatura de la emancipación en el Peru. En Revista Iberoamericana.

Editor. (1809). Comunicado de oficio a la Junta de Córdova. Minerva Peruana. Lima. $\mathrm{N}^{\circ} 35$.

Fernández, T. (1997). Teoría y crítica literaria de la emancipación hispanoamericana. Alicante. Instituto de Cultura "Juan Gil Albert".

Garibay, P. (1809). Don Pedro de Garibay, Mariscal... Minerva Peruana. Lima. N ${ }^{\circ}$. Penagós, J. L. (s.f.). El Mercurio Peruano y regionalismo. Lima.

Plinio. (1787). El panegírico de Plinio en Castellano, pronunciado en el Senado en alabanza del mejor Príncipe Trajano Agust, su filosofía política, moral y económica. En F. d. Barreda. Madrid. Imprenta de Don Antonio Espinoza. Imprenta del Ejercito Libertador. (1821). El Pacificador del Perú. Lima.

Ramos, L. M. (2007). Sociedad colonial y vida cotidiana en Lima través de las páginas del investigador (del Perú), 1813-1814. Lima. Colección Historia de la prensa peruana 1.

Ruiz, D. B. (1812). Señores editores. En El Peruano. Lima, 353.

Secrndi, P. C. (1328). Captulo II. En Epistolae et PANEGIRIVS. Roma. 
